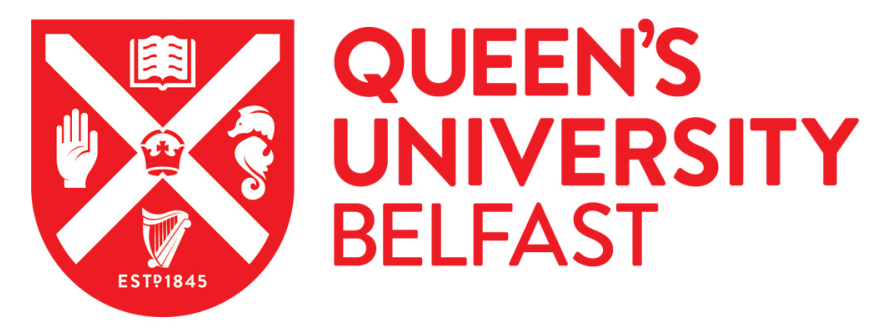

\title{
Scaling Considerations for 1-g Model Horizontal Plate Anchor Tests in Sand
}

\author{
Bradshaw, A. S., Giampa, J. R., Gerkus, H., Jalilvand, S., Fanning, J., Nanda, S., Gilbert, R., Gavin, K., \& \\ Sivakumar, V. (2016). Scaling Considerations for 1-g Model Horizontal Plate Anchor Tests in Sand. ASTM \\ Geotechnical Testing Journal, 39(6). https://doi.org/10.1520/GTJ20160042
}

Published in:

ASTM Geotechnical Testing Journal

Document Version:

Publisher's PDF, also known as Version of record

Queen's University Belfast - Research Portal:

Link to publication record in Queen's University Belfast Research Portal

Publisher rights

(c) 2017 ASTM. All Rights Reserved.

This work is made available online in accordance with the publisher's policies. Please refer to any applicable terms of use of the publisher.

\section{General rights}

Copyright for the publications made accessible via the Queen's University Belfast Research Portal is retained by the author(s) and / or other copyright owners and it is a condition of accessing these publications that users recognise and abide by the legal requirements associated with these rights.

Take down policy

The Research Portal is Queen's institutional repository that provides access to Queen's research output. Every effort has been made to ensure that content in the Research Portal does not infringe any person's rights, or applicable UK laws. If you discover content in the Research Portal that you believe breaches copyright or violates any law, please contact openaccess@qub.ac.uk. 


\section{Geotechnical Testing Journal}

A. S. Bradshaw, J. R. Giampa, ${ }^{2}$ H. Gerkus, ${ }^{3}$ S. Jalilvand, ${ }^{4}$ J. Fanning, ${ }^{5}$ S. Nanda, ${ }^{6}$ R. Gilbert, ${ }^{7}$ K. Gavin, ${ }^{8}$ and V. Sivakumar ${ }^{9}$

DOI: $10.1520 / G T J 20160042$

Scaling Considerations for $1-9$ Model Horizontal Plate Anchor Tests in Sand 
Manuscript received February 29, 2016; accepted for publication July 7, 2016; published online August 30, 2016.

' Univ. of Rhode Island, Kingston, RI 02881 (Corresponding author), e-mail: abrads@uri.edu

2 Univ. of Rhode Island, Kingston, RI 02881, e-mail: giampaj@gmail.com

${ }^{3}$ Univ. of Texas at Austin, Austin, TX 78712, e-mail: gerkus@utexas.edu

${ }^{4}$ Univ. College Dublin, Belfield, Dublin 4, Ireland, e-mail:

soroosh.jalilvand@gmail.com

${ }^{5}$ Queen's Univ. Belfast, Belfast BT7 1NN, United Kingdom, e-mail:

jfanning02@qub.ac.uk

${ }^{6}$ Queen's Univ. Belfast, Belfast BT7 1NN, United Kingdom, e-mail:

s.nanda@qub.ac.uk

'Univ. of Texas at Austin, Austin, TX 78712, e-mail:

bob_gilbert@mail.utexas.edu

${ }^{8}$ Delft University of Technology, Delft, Netherlands, e-mail: k.g.gavin@tudelft.nl

${ }^{9}$ Queen's Univ. Belfast, Belfast BT7 1NN, United Kingdom, e-mail: v.sivakumar@qub.ac.uk

\author{
A. S. Bradshaw, J. R. Giampa, ${ }^{2}$ H. Gerkus, ${ }^{3}$ S. Jalilvand, ${ }^{4}$ J. Fanning, ${ }^{5}$ S. Nanda, ${ }^{6}$ R. Gilbert, ${ }^{7}$ \\ K. Gavin, ${ }^{8}$ and V. Sivakumar ${ }^{9}$
}

\section{Scaling Considerations for 1-g Model Horizontal Plate Anchor Tests in Sand}

\section{Reference}

Bradshaw, A. S., Giampa, J. R., Gerkus, H., Jalilvand, S., Fanning, J., Nanda, S., Gilbert, R., Gavin, K., and Sivakumar, V., "Scaling Considerations for 1-g Model Horizontal Plate Anchor Tests in Sand," Geotechnical Testing Journal doi:10.1520/GTJ20160042. ISSN 0149-6115

\section{ABSTRACT}

This paper addresses scaling issues related to small-scale 1-g model tests on plate anchors in sand under drained loading conditions. Previous centrifuge studies from the literature have suggested that the results of conventional 1-g model testing are inaccurate because of scale effects. Other studies have suggested, however, that scaling errors can be reduced in 1-g model tests if the results are presented in dimensionless form and the constitutive response of the model soil is representative of the prototype behavior. There are no experimental studies in the literature that have tested the validity of this approach for plate anchors. A simple 1-g scaling framework was developed for vertically loaded, horizontal plate anchors. Small-scale 1-g model tests were performed on square plate anchors in dry sand, and combined with existing centrifuge and 1-g model test data from the literature to test the scaling approach for both capacity and deformation. The 1-g model tests provided a reasonable representation of the full-scale prototype behavior when the scaling approach was applied.

\section{Keywords}

marine anchors, plate anchors, 1-g model tests, scaling laws, sand

\section{Introduction}

Geotechnical engineering challenges will increase as the offshore renewable energy sector continues to move into new areas around the globe. The utilization of floating platforms to support offshore wind turbines is a relatively new concept. However, such energy platforms will require 
FIG. 1 Comparison of 1-g and centrifuge model test data on circular horizontal anchor plates in dry sand (after Ovesen 1981).

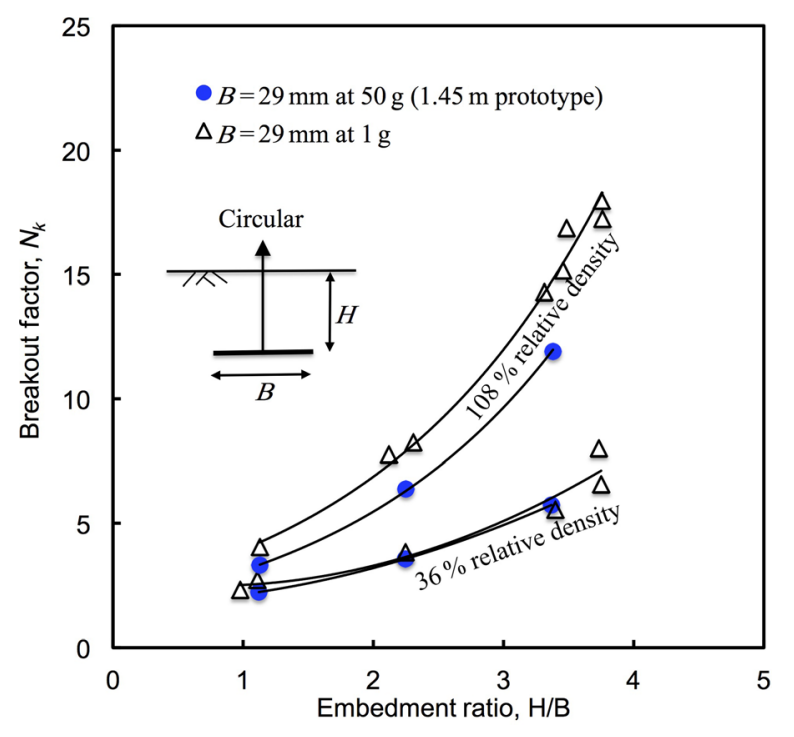

anchoring systems that at the present time are optimized for clays (e.g., Musial et al. 2004; Schneider and Senders 2010). Research is needed not only to optimize anchor performance in a wider range of soil conditions, but also to develop more sustainable and "green" anchor concepts (e.g., Gerkus et al. 2016). Plate-type anchors continue to be of interest because of their high efficiency in having high capacity-to-weight ratios.

Physical model testing provides a means to investigate foundations and anchors under carefully controlled conditions. Physical modeling is performed at $1 \mathrm{~g}$, at elevated stress levels in calibration chambers, or in the centrifuge at many times the earth's gravitational acceleration. The clear advantage to centrifuge testing is that it is possible to scale the stresses in the soil to represent the conditions in the full-scale (i.e., prototype) foundation. Centrifuges require large capital and operational investments and, thus, the main advantages to 1-g model testing are in the simplicity of equipment, greater flexibility, and lower cost.

It is important to address scaling issues in 1-g model tests as the data may be used to calibrate and validate numerical models of full-scale applications. Centrifuge studies on plate anchors by Ovesen (1981) and Dickin (1988) suggest that 1-g scale model results may be unreliable unless proper analytical methods are developed. This is shown by the data in Figs. 1 and 2, which compare the results of both conventional 1-g scale model tests with centrifuge model tests on both circular (Fig. 1) and square (Fig. 2) horizontal plate anchors. When sand was prepared to a constant relative density, the normalized anchor resistance (breakout factor, $N_{k}$ ) in the small-scale 1-g model tests were higher than in the centrifuge tests, inferring a scaling error. The error increases at higher relative densities and embedment ratios $(H / B)$. Although not shown in the figure, the
FIG. 2 Comparison of 1-g and centrifuge model test data on square horizontal anchor plates in dry sand (after Dickin 1988).

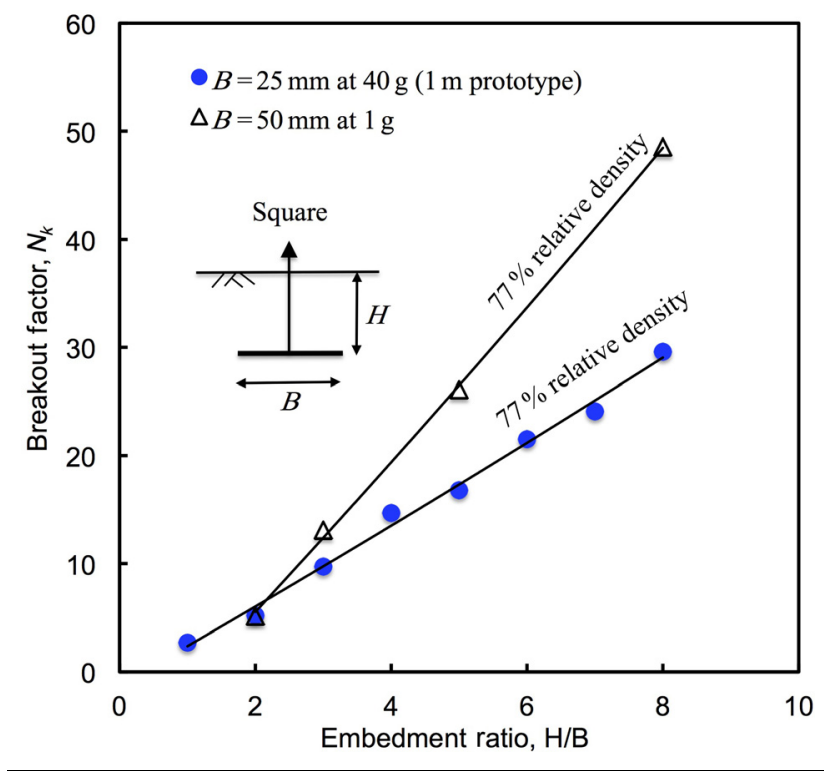

normalized displacements to failure in the 1-g model tests were higher than in the centrifuge at the same relative density.

Other researchers have proposed, however, that scaling effects can be minimized in 1-g model tests in sands by utilizing the natural dilative tendencies of the soil to "scale" the constitutive response. Altaee and Fellenius (1994) used a critical state framework to describe how a model soil may be prepared to scale the constitutive behavior. At constant void ratio, dilation will increase with a decrease in effective confining pressure. Therefore, if the model and prototype soils are prepared to the same void ratio, the model soil will be more dilative. Altaee and Fellenius (1994) suggested that the constitutive response of the model soil can be matched to the prototype by preparing the model soil to a looser state such that the soil is at the same distance from the critical state line. They proposed a scaling equation for void ratio based on the slope of the critical state line and the geometric scaling ratio of the model.

Kelly et al. (2006) scaled 1-g model tests on caisson foundations by plotting the test results in terms of dimensionless load and displacement. LeBlanc et al. (2010) also used a dimensionless framework in combination with constitutive scaling to study the behavior of monopiles under lateral loading. They developed dimensionless equations that related lateral load and displacements. The model soil was prepared at a lower relative density than the prototype such that the peak friction angle matched that of the prototype soil. The peak friction angles were interpreted using a soil-specific correlation relating peak friction angle to relative density and effective isotropic stress that was obtained from triaxial tests on the model soil.

Although the scaling approaches described above are theoretically rigorous, there are few experimental data that support 
their validity. This is not unreasonable considering that most 1-g model tests are performed because there may not be full-scale test data available. This study is prompted by a research project on offshore anchor systems wherein the authors are utilizing 1-g model tests in combination with centrifuge testing, offshore prototype scale trial, and finite element modeling to study the behavior of plate anchors for marine applications. The hypothesis is that scaling effects will be eliminated in 1-g model tests if the results are presented in a dimensionless framework and the constitutive behavior is scaled to match the prototype. The objective, therefore, is to test this hypothesis by presenting a dimensionless scaling framework for horizontal plates and comparing the results of 1-g model and centrifuge test data available in the literature that will serve as the "prototype." The remaining sections of the paper present the dimensionless scaling equations and an evaluation of the scaling approach.

\section{Dimensionless Scaling Equations}

The proposed scaling approach for the 1-g model testing of plate anchors under drained conditions involves presenting the data in dimensionless form in combination with scaling of the soil constitutive behavior. A simple dimensionless framework for a vertically loaded plate anchor was derived starting with the general form of the elastic solution for a finite loaded area:

$$
d=\frac{q B}{E} I
$$

where:

$d=$ displacement,

$E=$ equivalent elastic modulus,

$q=$ bearing pressure,

$B=$ foundation width, and

$I=$ displacement influence factor.

The influence factor would include the effects of foundation shape, foundation embedment ratio, and Poisson's ratio that will be the same in both the model and prototype. Dividing both sides by the unit weight and embedment depth, $\gamma H$, and rearranging the equation yields the following simple dimensionless expression for the load-displacement behavior of a plate anchor:

$$
\underbrace{\frac{q}{\gamma H}}_{\tilde{Q}}=\underbrace{\frac{E}{I \gamma H}}_{\tilde{E}} \underbrace{\frac{d}{B}}_{\tilde{D}}
$$

where:

$\tilde{Q}=$ dimensionless bearing pressure,

$\tilde{E}=$ dimensionless modulus, and

$\tilde{D}=$ dimensionless displacement.

The ultimate value of $\tilde{Q}$ in Eq 2 corresponds to the breakout factor $\left(N_{k}\right)$, commonly used in numerous theoretical and experimental plate anchor studies from the literature where:

$$
N_{k}=\frac{q_{u}}{\gamma H}
$$

where:

$q_{u}=$ ultimate bearing capacity of the plate. Note that the buoyant unit weight would be used in Eq 3 for submerged conditions.

Theoretical studies on anchor plates assuming nonassociated flow (e.g., Rowe and Davis 1982; White et al. 2008; Giampa et al. 2016), for example, indicate that $N_{k}$ depends on peak friction angle, critical state friction angle, peak dilation angle, and embedment ratio $(H / B)$. The dilation angle is particularly important in shallow anchors because it controls the size and shape of the failure wedge.

The constitutive model developed by Bolton (1986) considers the effect of confining pressure and relative density on strength and dilatancy. The state of the soil is defined by the relative dilatancy index having the following general form:

$$
I_{R}=I_{D}\left[Q-\ln \left(p_{f}^{\prime}\right)\right]-R
$$

where:

$I_{R}=$ relative dilatancy index,

$I_{D}=$ relative density index $=\left(e_{\max }-e\right) /\left(e_{\max }-e_{\min }\right)$,

$e=$ void ratio,

$e_{\max }, e_{\min }=$ maximum and minimum void ratios,

$p_{f}^{\prime}=$ mean effective confining pressure at failure (in $\mathrm{kPa}$ ), and

$Q$ and $R=$ constants.

The relative dilatancy index is empirically related to strength by the following equation:

$$
\phi_{p}^{\prime}-\phi_{c}^{\prime}=\alpha I_{R}
$$

where:

$\phi_{p}^{\prime}=$ peak friction angle,

$\phi_{c}^{\prime}=$ critical state friction angle, and

$\alpha=$ constant (three for triaxial and five for plane-strain conditions).

Using a large database of element tests, Bolton (1986) suggested values for $Q$ and $R$ of 10 and 1, respectively, and that $I_{R}$ should be limited to between 0 and 4 . Bolton (1986) also indicated that $Q$ and $R$ could be calibrated to a specific soil. In a 1-g model test, it is important to characterize the behavior at low confining stress levels. Chakraborty and Salgado (2010) investigated Bolton's parameters at low initial confining pressures from 4 to $197 \mathrm{kPa}$ in Toyoura sand and found that $\alpha$ was 3.8 for both plane strain and triaxial conditions. This constant value was adopted for this study.

The peak dilation angle $\psi_{p}$, which typically occurs at the peak strength (Bolton 1986), is also related to strength and $I_{R}$ by the following:

$$
\phi_{p}^{\prime}-\phi_{c}^{\prime}=\beta \psi_{p}
$$


where:

$\beta=$ a constant.

Bolton (1986) suggested a $\beta$ of 0.8 for plane strain because it agreed with Rowe's stress-dilatancy relationship for plane strain. However, Chakraboty and Salgado (2010) suggested a $\beta$ value of approximately 0.6 for both triaxial and plane strain at low stress levels.

Equations 4, 5, and 6 suggest that, for non-associated flow at a constant $H / B$, the breakout factor theoretically should be a unique function of $I_{R}$ and $\phi_{c}^{\prime}$. For most quartz and silica sands, $\phi_{c}^{\prime}$ varies over a very small range $\left(\sim 32^{\circ}\right.$ to $\left.34^{\circ}\right)$. If the model and prototype consist of the same soil, $\phi_{c}^{\prime}$ is constant, and, thus, a model test should yield the same $N_{k}$ as a prototype if the model soil is prepared to the same $I_{R}$ as the prototype. By equating the $I_{R}$ in the model and prototype in the same soil, it is possible to derive a scaling equation for void ratio:

$$
e_{m}=e_{\max }-\frac{Q-\ln \left(p_{f p}^{\prime}\right)}{Q-\ln \left(p_{f m}^{\prime}\right)}\left(e_{\max }-e_{p}\right)
$$

where:

$e_{m}=$ void ratio of model soil,

$e_{p}=$ void ratio of prototype soil,

$p_{f m}^{\prime}=$ mean effective confining pressure at failure in the model, and

$p_{f p}^{\prime}=$ mean effective confining pressure at failure in the prototype.

To achieve a similar dimensionless deformation response, the value of $\widetilde{E}$ must be the same in the model and the prototype. Setting $\tilde{E}$ in the model and prototype equal and assuming that the displacement influence factor is identical in the model and prototype, the following scaling equation for soil modulus is derived:

$$
\frac{E_{m}}{E_{p}}=\frac{\gamma_{m} H_{m}}{\gamma_{p} H_{p}}
$$

where:

$E_{m}=$ equivalent elastic modulus of the model,

$E_{p}=$ equivalent elastic modulus of the prototype,

$\gamma_{m}=$ unit weight of model soil,

$\gamma_{p}=$ unit weight of prototype soil,

$H_{m}=$ embedment depth of model anchor, and

$H_{p}=$ embedment depth of prototype anchor.

The modulus of soil is influenced primarily by effective confining pressure, void ratio, fabric, and strain level. Consistent with the form proposed by Jamiolkowski et al. (1991) for small-strain shear modulus, the following equation was used in this study to model the elastic modulus: $E=A e^{m}\left(p^{\prime}\right)^{0.5}$, where $e=$ void ratio, $p^{\prime}=$ mean effective confining pressure, and $A$ and $m=$ soil-specific constants. Substituting this relationship into Eq 8 for both the model and prototype and assuming that $\mathrm{p} \sim \gamma \mathrm{H}$ leads to the following scaling equation for void ratio:

$$
e_{m}=e_{p}\left[\left(\frac{p_{m}^{\prime}}{p_{p}^{\prime}}\right)^{0.5}\right]^{1 / m}
$$

where:

$p_{m}^{\prime}=$ mean effective confining pressure in the model, and $p_{p}^{\prime}=$ mean effective confining pressure in the prototype.

Both the scaling equation for strength (Eq 7) and modulus (Eq 9) indicate that the soil in the model must be prepared looser than in the prototype. However, given that the scaling relationships are different, it would be difficult to achieve both strength and stiffness scaling simultaneously in a model test.

\section{Other Scaling Considerations}

There are two other scaling issues that must be considered in the physical modeling of plate anchors in sand. The first scaling issue is the grain size effects on soil-structure interaction. The requirement is that there must be a sufficient number of particles over the width of the plate such that it can be modeled as a continuum. Current centrifuge scaling laws for grain size suggest that scaling effects can be minimized by keeping the ratio of the plate width $(B)$ to the mean particle size $\left(d_{50}\right)$ of the soil below a value of 48 (Garnier and Gaudin 2007).

The second scaling issue is on the particle size effects on interfaces and shear band patterns. Numerical studies by Rowe and Davis (1982) on plate anchors demonstrated that interface friction does not affect the capacity in horizontal plates, but does increase capacity in shallow vertical plates at embedment ratios $(H / B)$ of less than 5 . To preserve interface similitude, current scaling laws suggest that the ratio of the foundation surface roughness to $d_{50}$ should be kept constant in the model and prototype (Garnier and Gaudin 2007).

\section{Evaluation of the Scaling Approach}

\section{1-g MODEL TESTING}

A series of 1-g model tests were performed at the University of Rhode Island (URI) on vertically loaded horizontal square plate anchors embedded in dry sand. A schematic of the test setup is shown in Fig. 3. The sand was obtained from a natural deposit in Westerly, RI, and consisted of uniform quartz grains with the index properties given in Table 1. The square anchor plates were fabricated from structural steel with widths of $152.4 \mathrm{~mm}$ and $304.8 \mathrm{~mm}$ and a thickness of $12.7 \mathrm{~mm}$. The ratio of anchor width to the $d_{50}$ of the sand satisfied the grain-size scaling considerations.

The sand was dry pluviated into a rigid test container (2.4-m length $\times 1.2-\mathrm{m}$ width $\times 0.9-\mathrm{m}$ height $)$ using a portable pluviator based on Gade et al. (2013). The pluviation device consisted of a bucket attached to a flexible hose leading to a pipe containing a plate with holes and a stack of sieves. The unit weight of the deposited soil was determined by pluviating sand into small cups of a known volume $\left(413 \mathrm{~cm}^{3}\right)$ that were 
FIG. 3 Schematic of the anchor test setup used in this study.

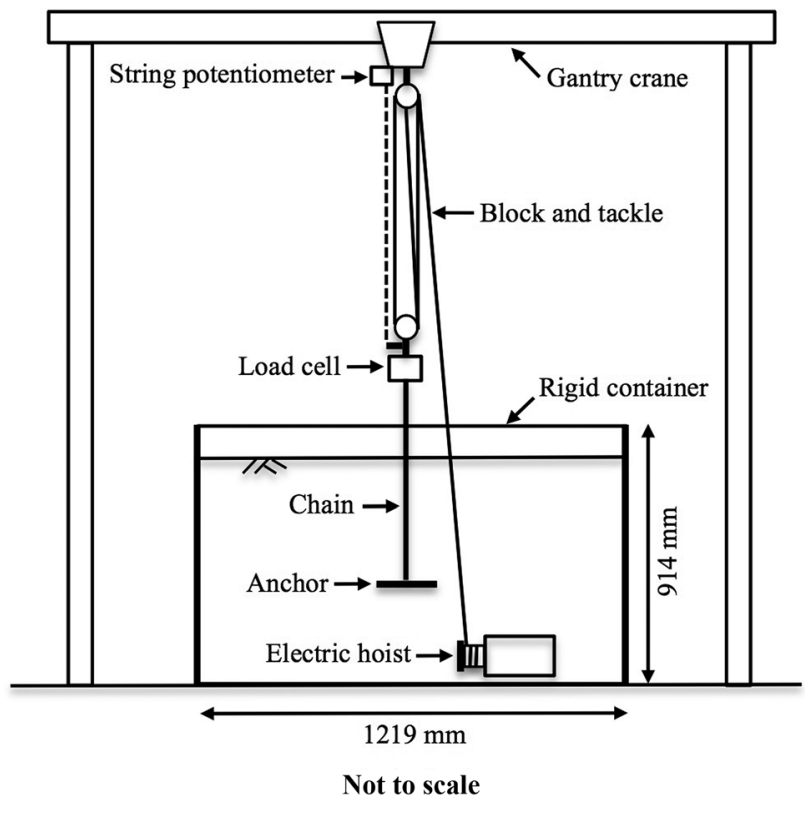

placed on the soil surface at various depths during sand placement. The unit weights measured during preparation of one of the test containers are shown in Fig. 4a along with the corresponding calculated relative densities in Fig. $\mathbf{4 b}$. The relative densities were fairly consistent throughout the container with a coefficient of variation of less than 0.2 .

The plate anchors were placed at embedment ratios of 1 to 5 during soil pluviation. The plates were also spaced at a distance of at least $3 B$ from the walls of the test container and the adjacent anchors to minimize interaction. The anchors were pulled out at a constant rate of $50 \mathrm{~mm} / \mathrm{s}$ using an electric hoist, and a block and tackle system as shown in Fig. 3. Loads were measured with a load cell with a capacity of $0.89,2.2$, or $11.1 \mathrm{kN}$ (CAS SBA and Omega LC), and displacements were measured with a string potentiometer (measurement specialties SP2-50). The loading rate was significantly higher than other studies (e.g., Murray and Geddes 1987) but strain rates have been shown to have a negligible effect on the strength of dry sand (e.g., Whitman and Healy 1962).

TABLE 1 Summary of index properties of the sands used in this study.

\begin{tabular}{lcc}
\hline Parameter & Westerly & Erith \\
\hline$\gamma_{\max }\left(\mathrm{kN} / \mathrm{m}^{3}\right)$ & 18.1 & 17.3 \\
$\gamma_{\min }\left(\mathrm{kN} / \mathrm{m}^{3}\right)$ & 14.1 & 14.3 \\
$e_{\min }$ & 0.44 & 0.52 \\
$e_{\max }$ & 0.84 & 0.98 \\
$d_{50}(\mathrm{~mm})$ & 0.3 & $\sim 0.2$ \\
$G_{s}$ & 2.65 & 2.65 \\
\hline
\end{tabular}

Note: Data on Erith sand was compiled from Dickin (1988).
FIG. 4 Typical profiles of: (a) unit weight, and (b) relative density obtained within the test container.

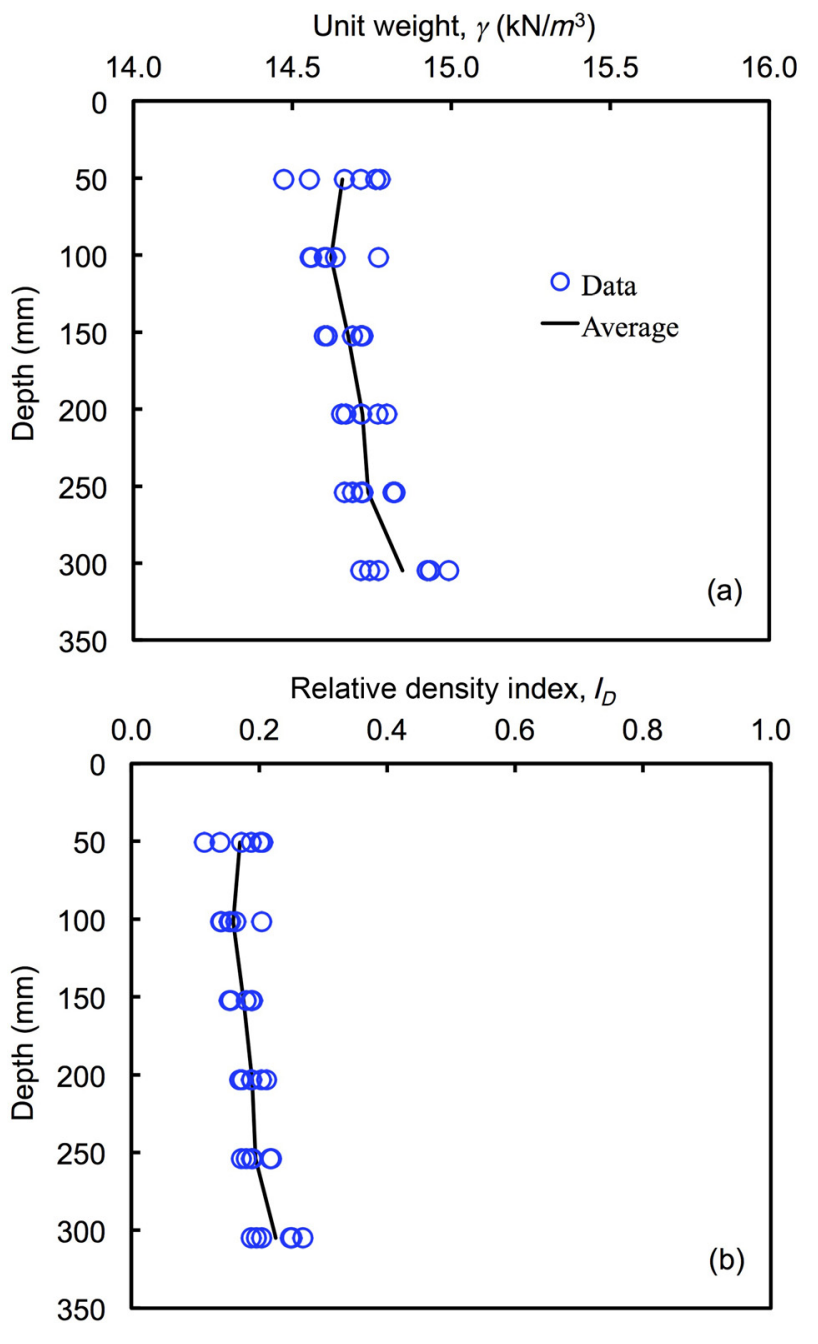

EXISTING CENTRIFUGE AND 1-g MODEL TEST DATA

This study used the existing centrifuge data available in the literature as the "prototype" anchor. Only one centrifuge plate anchor study was identified, reported by Dickin (1988) who also reported triaxial data, which allowed a detailed calibration of Bolton's equation. Dickin (1988) also performed some conventional 1-g model testing in the same soil. Only the square anchor plate data were utilized in this study, as this is most similar to the plate anchor geometry that might be used in a marine anchoring application. Dickin's anchor tests were performed in dry Erith sand whose index properties are summarized in Table 1. The loose soils in Dickin's study were prepared by soil raining from a tray with holes, whereas the dense soils were prepared by vibratory compaction in 25-mm layers.

Dickin (1988) used stainless steel plates with a width of $25 \mathrm{~mm}$ in the centrifuge (1-m prototype) and $50 \mathrm{~mm}$ in the $1-\mathrm{g}$ model tests. Tests were performed using a loading rate of 
$0.23 \mathrm{~mm} / \mathrm{min}$ at relative density indices of 0.34 and 0.77 . The ratio of $d_{50}(\sim 0.2 \mathrm{~mm})$ to the plate width satisfies the grain-size scaling in both cases.

\section{CALIBRATION OF BOLTON'S PARAMETERS}

Triaxial tests were performed to calibrate Bolton's parameters $Q$ and $R$ for the Westerly sand. Triaxial samples were prepared using dry pluviation with a funnel in an attempt to achieve a similar fabric as the sand in the physical model tests. A range of relative densities could be achieved by varying the size of the funnel tube.

Two types of triaxial tests were performed on the Westerly sand. The first type consisted of conventional consolidated drained (CD) triaxial tests where the volume change behavior was measured using a burette system that allowed the calculation of dilation angles. The samples were sheared after a $B$-parameter of at least 0.93 was achieved. In the second type of test, a vacuum was applied to the sample to achieve very low confining pressures down to $8 \mathrm{kPa}$. No volume change measurements were made. All tests were performed on 72-mm-diameter samples. The $\phi_{c}^{\prime}$ of the Westerly sand was determined from extrapolating the peak friction angle at zero dilation angle (Bolton 1986) and $Q$ and $R$ were determined from the linear regression plot shown in Fig. 5. All parameters are summarized in Table 2. As shown in Table 2, the $\beta$ was similar to the value $\sim 0.6$ reported by Chakraboty and Salgado (2010) at low confining pressures.

Triaxial data on Erith sand were compiled from Dickin and Leung (1983) and Dickin (1988). The test data covered the full range of stress conditions from the 1-g model to the prototype scales. Dilation angle was not provided and thus the critical state friction angle was assumed to be $33^{\circ}$, that is slightly lower

FIG. 5 Calibration plot of triaxial test data for Westerly sand.

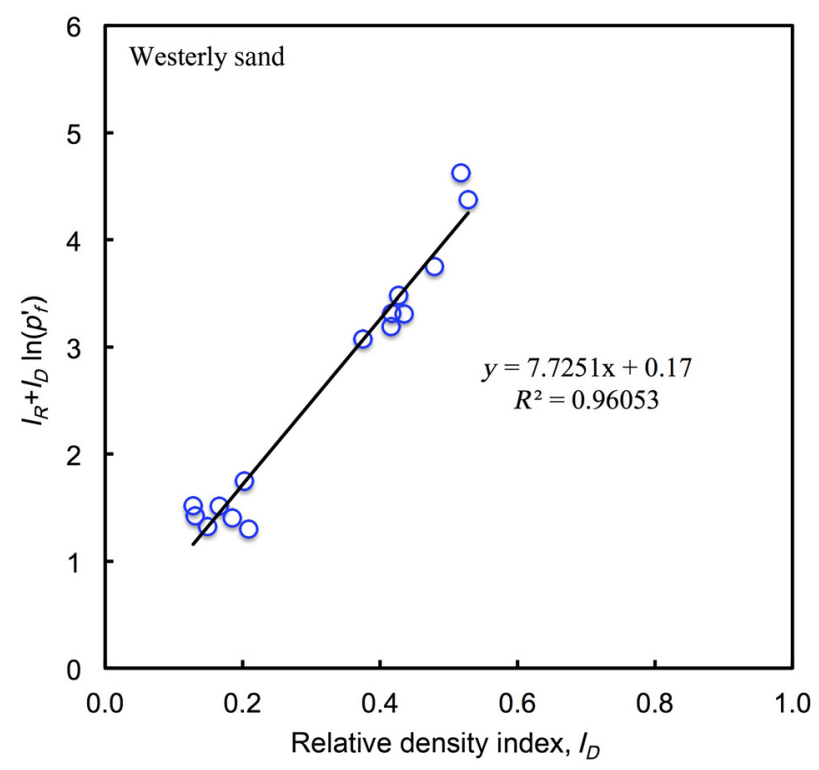

TABLE 2 Summary of calibration parameters for the sands used in this study

\begin{tabular}{lcc}
\hline Parameter & Westerly & Erith \\
\hline$\phi_{\mathrm{c}}^{\prime}$ & $32.3^{\circ}$ & $33^{\circ}$ (assumed) \\
$Q$ & 7.73 & 8.61 \\
$R$ & -0.17 & 0.19 \\
$\beta$ & 0.68 & 0.6 (assumed) \\
\hline
\end{tabular}

than the peak friction angle measured in the loosest sample at the highest confining pressure. This is consistent with typical values for quartz sand of $\sim 33^{\circ}$ (Bolton 1986). The $Q$ and $R$ for the Erith sand was obtained from Fig. $\mathbf{6}$, and all parameters are summarized in Table 2.

\section{Results and Discussion}

Typical normalized pressure-displacement curves are plotted in Fig. 7 for three different $H / B$ ratios at constant relative density. As shown in the figure, the resistance reaches a clear peak and then reduces as the anchor is pulled out of the soil. The bearing capacity factor $N_{k}$ was determined at the peak resistance, and was found to increase with $H / B$ as the failure wedge increases and the anchor transitions toward a more localized "deep" failure mode. The dimensionless displacement at failure $\left(d_{f} / B\right)$ also increases with $H / B$ because there is a larger volume of soil that is being strained, thus resulting in higher displacements.

Figs. 8 through 10 plot $N_{k}$ versus $I_{R}$ at embedment ratios of 1,3 , and 5 , respectively. The figures combine data from the 1-g model tests performed in Westerly sand in this study as well as 1-g and centrifuge test results in Erith sand reported by Dickin

FIG. 6 Calibration plot of triaxial test data for Erith sand (data from Dickin and Leung 1983 and Dickin 1988).

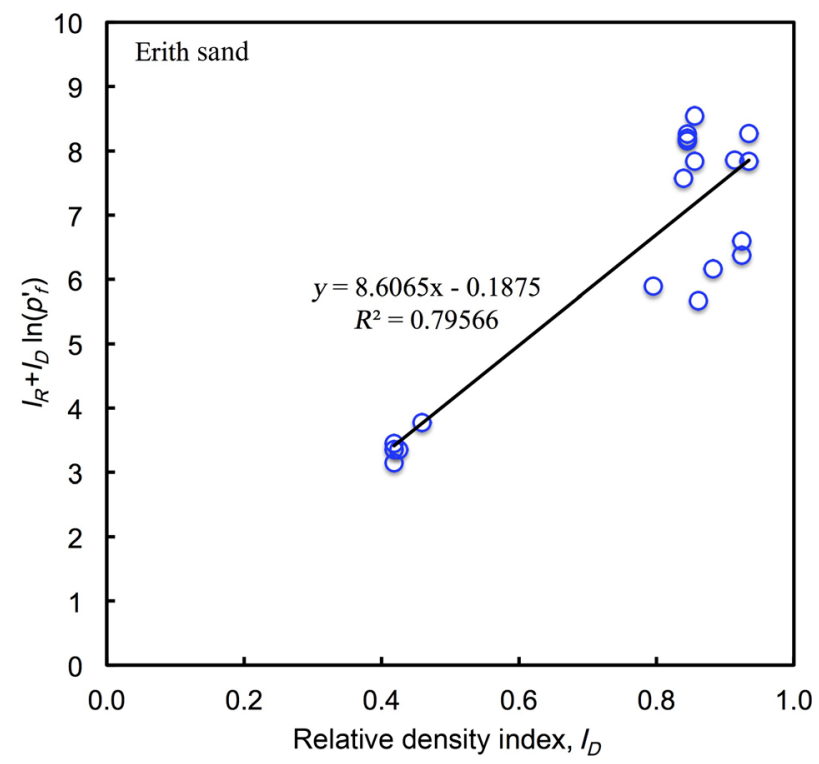


FIG. 7 Typical load-displacement curves for the anchor tests performed in this study.

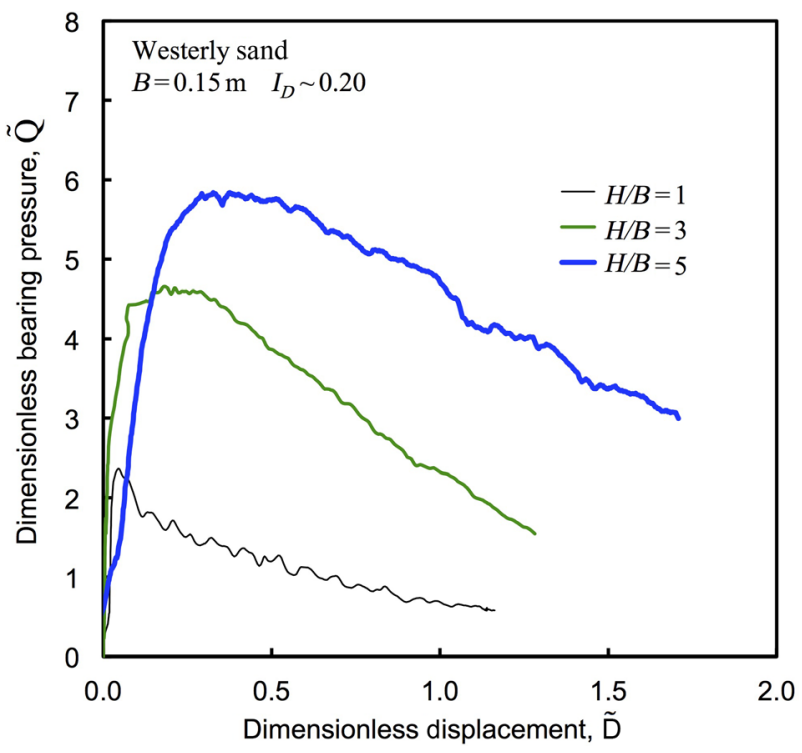

(1988). The $I_{R}$ was calculated assuming $p_{f}^{\prime}=\gamma H$ to account for the increase in vertical stress in the soil above the anchor during loading (White et al. 2008). To show the expected trends, the analytical solutions by Rowe and Davis (1982) for nonassociated flow are also plotted on the figures. Their solutions are for plane strain and were adjusted using empirical shape factors for plates by Dickin (1988).

As shown in Figs. 8 through 10, the analytical solutions for the Westerly and Erith sands are very similar, which is attributed to the slight difference in $\phi_{c}^{\prime}$ between the two soils. The

FIG. 8 Comparison of breakout factors from centrifuge and 1-g model tests on horizontal square plate anchors for $H / B=1$ (test data on Erith sand is from Dickin 1988).

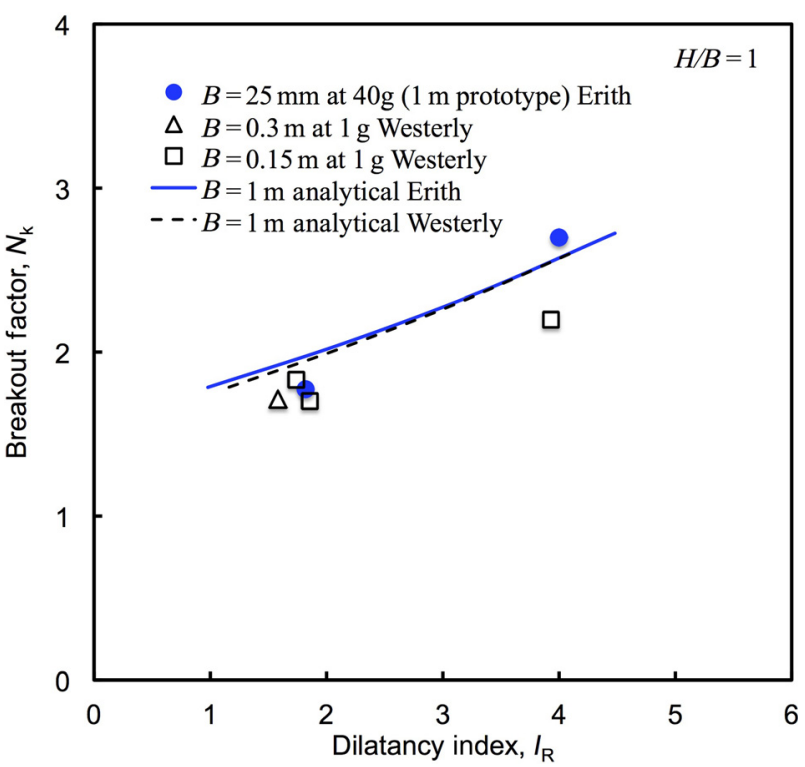

FIG. 9 Comparison of breakout factors from centrifuge and 1-g model tests on horizontal square plate anchors for $H / B=3$ (test data on Erith sand is from Dickin 1988)

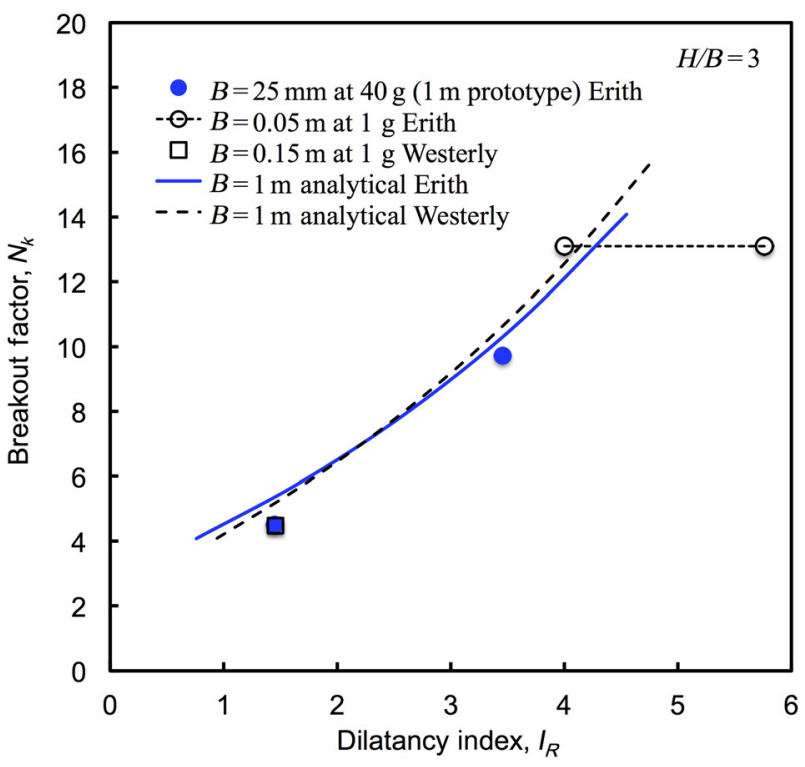

results also show that the $N_{k}$ obtained from both the 1-g model and centrifuge tests plot closely with the analytical trends. In two of the 1-g model tests on Erith sand $(B=0.05 \mathrm{~m})$, the analysis predicted $I_{R}$ values over 4 . This exceeded both the $I_{R}$ measured in the triaxial tests and the maximum value of 4 suggested by Bolton (1986). To show this uncertainty in the tests, the range of $I_{R}$ is plotted as two points connected with a dashed line in Figs. 9 and 10. The results suggest that limiting the $I_{R}$ to 4 would make the 1-g test results more consistent with the theoretical trends. Generally, the data in Figs. 8 through 10 supports the validity of the scaling approach for anchor capacity.

Soil modulus depends primarily on confining stress, void ratio, and fabric that is unique to a specific soil. Therefore, scaling of the modulus was only investigated for the Erith sand that allowed a comparison between the 1-g model and centrifuge test data from the same soil. A secant value of the dimensionless modulus, $\tilde{E}$, at failure was calculated for the anchor test data by taking the ratio of the $N_{k}$ to $d_{f} / B$. Fig. 11 plots $\tilde{E}$ at failure for both the 1-g model and centrifuge tests for $H / B$ ranging from 1 to 8 . To demonstrate the effect of the modulus scaling, it was necessary to extrapolate the centrifuge test data to lower values of void ratio. To do this, the equation for $E$ presented earlier was substituted into the equation for $\tilde{E}$ (Eq 2) to obtain the following:

$$
\tilde{E}=B e^{m}\left(p^{\prime}\right)^{-0.5}
$$

where:

$B=$ constant combining the constants $A$ and $I$.

Values of 65 and -5 for $B$ and $m$, respectively, provided a reasonable fit to the centrifuge data and were used to generate the upper- and lower-bound curves shown in Fig. 11. The 


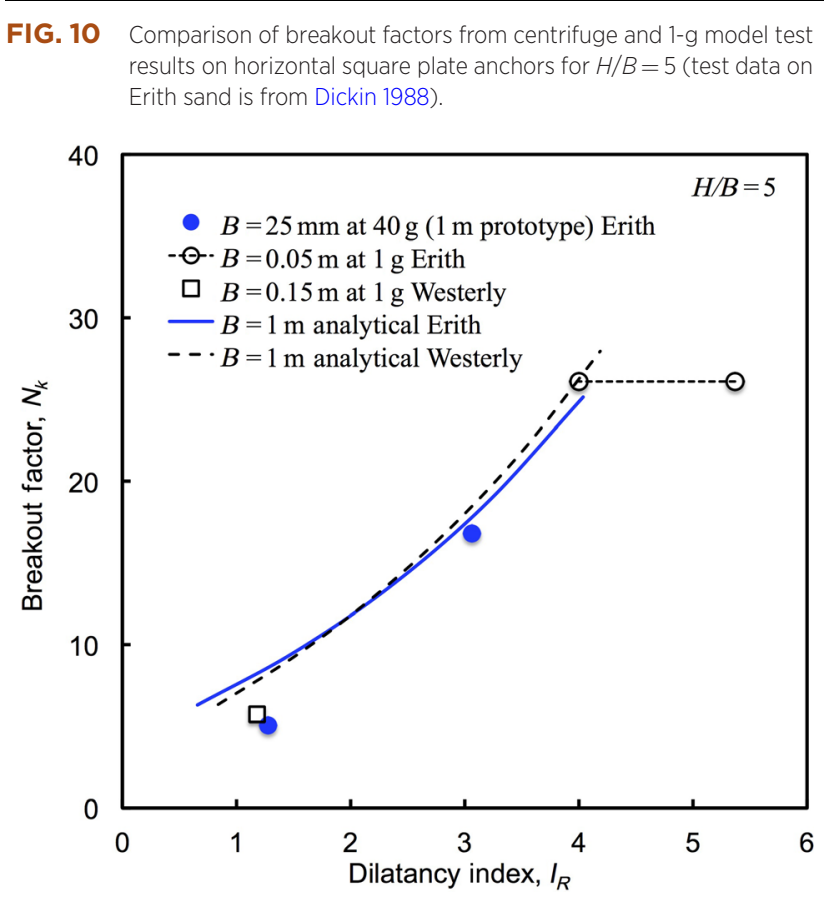

two curves correspond to $H / B$ of 1 and 8 , respectively, and, therefore, represent the range of anticipated behavior for a $1-\mathrm{m}$ wide square anchor plate in Erith sand.

As shown in Fig. 11, $\tilde{E}$ at failure from the 1-g model tests performed using the 0.05 -m-wide anchor plates plot to the right of the prototype curves, suggesting that the 1-g model tests will likely overpredict modulus and underpredict deformation of the prototype if no scaling is applied. To test the scaling approach, Eq 9 was used to calculate the void ratio corresponding to the

FIG. 11 Dimensionless modulus calculated from centrifuge and 1-g model test results on horizontal square plate anchors in Erith sand (test data from Dickin 1988).

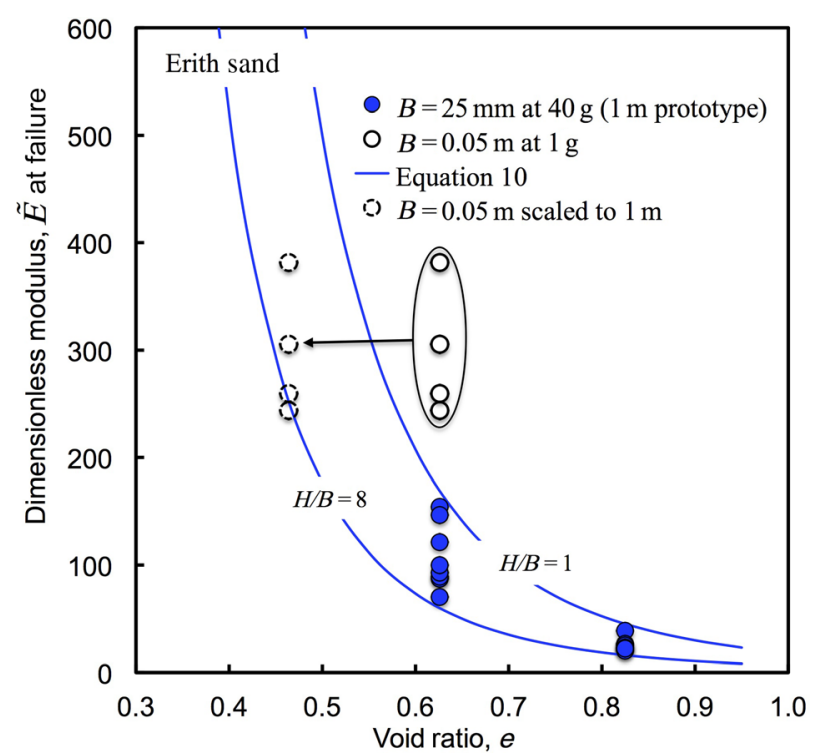

1-m prototype anchor. As shown in Fig. 11, this had the effect of reducing the void ratio from 0.63 to 0.46 , which shifted the data into the anticipated range of prototype behavior. The data in Fig. 11, therefore, supports the validity of the scaling approach for anchor deformation.

\section{Conclusions}

A number of studies in the literature have suggested that conventional 1 -g model tests can be used to simulate prototype behavior if the results are presented in dimensionless form and the constitutive response of the soil is similar to the prototype. The objective of this study was to test this hypothesis for vertically loaded horizontal plate anchors in sand. Simple dimensionless scaling equations were derived for a horizontal plate anchor both for capacity and deformation under drained loading conditions. Centrifuge and 1-g model tests were compiled from the literature and additional 1 -g model tests were performed in dry sand. The results suggested that 1 -g model testing provides a reasonable representation of prototype behavior if proper scaling equations are applied. Representative capacities can be achieved by presenting the peak resistance in dimensionless form, $N_{k}$, and preparing the model soil to the same dilatancy index as the prototype. Representative deformation behavior can be achieved by preparing the model soil to the same dimensionless modulus as the prototype. However, because the equations for scaling anchor capacity and deformation are different, it will be difficult to achieve both capacity and deformation similitude simultaneously in a 1-g model test.

\section{ACKNOWLEDGMENTS}

This material is based upon work supported by the National Science Foundation under Grant No. 1300142 and also by the Science Foundation Ireland under the U.S.-Ireland R\&D Partnership Program Grant No. SFI/2012/US/E2479.

\section{References}

Altaee, A. and Fellenius, B. H., 1994, "Physical Modeling in Sand," Can. Geotech. J., Vol. 31, No. 3, pp. 420-431.

Bolton, M. D., 1986, "The Strength and Dilatancy of Sands," Geotechnique, Vol. 36, No. 1, pp. 65-78.

Chakraborty, T. and Salgado, R., 2000, "Dilatancy and Shear Strength of Sand at Low Confining Pressures," J. Geotech. Geoenviron. Eng., Vol. 136, No. 3, pp. 527-532.

Dickin, E. A., 1988, "Uplift Behavior of Horizontal Anchor Plates in Sand," J. Geotech. Eng., Vol. 114, No. 11, pp. $1300-1317$.

Dickin, E. A. and Leung, C. F., 1983, "Centrifugal Model Tests on Vertical Anchor Plates," J. Geotech. Eng., Vol. 109, No. 12, pp. 1503-1525.

Gade, V. K., Dave, T. N., Chauhan, V. B., and Daska, S. M., 2013, "Portable Traveling Pluviator to Reconstitute Specimens of Cohesionless Soils," Proc. of Indian Geotechnical Conference, IGS, University in Roorkee, India. 
Garnier, J., Gaudin, C., Springman, S. M., Culligan, P. J., Goodings, D., Konig, D., Kutter, B., Phillips, R., Randolph, M. F., and Thorel, L., 2007, "Catalogue of Scaling Laws and Similitude Questions in Geotechnical Centrifuge Modeling," Int. J. Phys. Modell. Geotech., Vol. 7, No. 3, pp. 1-23.

Gerkus, H., Giampa, J. R., Senanayake, A. I., Lai, Y., Huang, Y., Flores, J. E. I., Breithaupt, B., Sivarajah, S., Bradshaw, A. S., and Gilbert, R. B., 2016, "Preliminary Development of a New Concept to Improve Sustainability of Offshore Foundations," Proceedings of the ASCE Geo-Chicago 2016 Conference, Chicago, IL, August 14-18, 2016.

Giampa, J., Bradshaw, A. S., and Schneider, J., 2016, "Influence of Dilation Angle on Drained Shallow Circular Anchor Uplift Capacity," Int. J. Geomech., 10.1061/(ASCE)GM.19435622.0000725, 04016056.

Jamiolkowski, M., Leroueil, S., and Lo Presti, D. C. F., 1991, "Theme Lecture: Design Parameters From Theory to Practice," Proceedings of Geo-Coast'91, pp. 1-41.

Kelly, R. B., Houlsby, G. T., and Byrne, B. W., 2006, "A Comparison of Field and Laboratory Tests of Caisson Foundations in Sand and Clay," Geotechnique, Vol. 56, No. 9, pp. 617-626.
LeBlanc, C., Houlsby, G. T., and Byrne, B. W., 2010, "Response of Stiff Piles in Sand to Long-Term Cyclic Lateral Loading," Geotechnique, Vol. 60, No. 2, pp. 79-90.

Murray, E. J. and Geddes, J. D., 1987, "Uplift of Anchor Plates in Sand," ASCE J. of Geotech. Eng., Vol. 113, No. 3, 202-215.

Musial, W., Butterfield, S., and Boone, A., 2004, "Feasibility of Floating Platform Systems for Wind Turbines," 23rd ASME Wind Energy Symposium, Reno, NV, Jan 5-8.

Ovesen, N. K., 1981, "Centrifuge Tests of the Uplift Capacity of Anchors," Proceedings of the 10th International Conference on Soil Mechanics and Foundation Engineering, pp. 717-722.

Rowe, R. K. and Davis, E. H., 1982, "The Behaviour of Anchor Plates in Sand," Geotechnique, Vol. 32, No. 1, pp. 25-41.

Schneider, J. A. and Senders, M., 2010, "Foundation Design: A Comparison of Oil and Gas Platforms With Offshore Wind Turbines," Marine Technol. Soc. J., Vol. 44, No. 1, pp. 32-51.

White, D. J., Cheuk, C. Y., and Bolton, M. D., 2008, "The Uplift Resistance of Pipes and Plate Anchors Buried in Sand," Geotechnique, Vol. 58, No. 10, pp. 771-779.

Whitman, R. V. and Healy, K. A., 1962, "Shear Strength of Sands During Rapid Loadings," J. Soil Mech. Found. Div., Vol. 88, No. SM2, pp. 99-131. 